ఠ

Open Access Full Text Article

\title{
New insights into the mechanisms of action of aspirin and its use in the prevention and treatment of arterial and venous thromboembolism
}

This article was published in the following Dove Press journal:

Therapeutics and Clinical Risk Management

24 September 2015

Number of times this article has been viewed

Ymer H Mekaj ${ }^{1,2}$

Fetije T Daci

Agon Y Mekaj ${ }^{3}$

'Institute of Pathophysiology, Faculty of Medicine, University of Prishtina, ${ }^{2}$ Department of Hemostasis and Thrombosis, National Blood

Transfusion Center of Kosovo, ${ }^{3} \mathrm{Clinic}$ of Neurosurgery, Faculty of Medicine, University of Prishtina, Prishtina, Kosovo
Correspondence: Agon Y Mekaj

Clinic of Neurosurgery, Faculty of Medicine, University of Prishtina, Rrethi i Spitalit pn, Prishtina 10000, Kosovo Tel +37744373545

Email agon.mekaj@uni-pr.edu
Abstract: The antithrombotic action of aspirin has long been recognized. Aspirin inhibits platelet function through irreversible inhibition of cyclooxygenase (COX) activity. Until recently, aspirin has been mainly used for primary and secondary prevention of arterial antithrombotic events. The aim of this study was to review the literature with regard to the various mechanisms of the newly discovered effects of aspirin in the prevention of the initiation and development of venous thrombosis. For this purpose, we used relevant data from the latest numerous scientific studies, including review articles, original research articles, double-blinded randomized controlled trials, a prospective combined analysis, a meta-analysis of randomized trials, evidencebased clinical practice guidelines, and multicenter studies. Aspirin is used in the prevention of venous thromboembolism (VTE), especially the prevention of recurrent VTE in patients with unprovoked VTE who were treated with vitamin K antagonists (VKAs) or with non-vitamin $\mathrm{K}$ antagonist oral anticoagulants (NOACs). Numerous studies have shown that aspirin reduces the rate of recurrent VTE in patients, following cessation of VKAs or NOACs. Furthermore, low doses of aspirin are suitable for long-term therapy in patients recovering from orthopedic or other surgeries. Aspirin is indicated for the primary and secondary prevention as well as the treatment of cardiovascular diseases, including acute coronary syndrome, myocardial infarction, peripheral artery disease, acute ischemic stroke, and transient ischemic attack (especially in atrial fibrillation or mechanical heart valves). Aspirin can prevent or treat recurrent unprovoked VTEs as well as VTEs occurring after various surgeries or in patients with malignant disease. Recent trials have suggested that the long-term use of low-dose aspirin is effective not only in the prevention and treatment of arterial thrombosis but also in the prevention and treatment of VTE. Compared with VKAs and NOACs, aspirin has a reduced risk of bleeding.

Keywords: arterial thrombosis, cyclooxygenase inhibitor, recurrent VTE, platelet

\section{Introduction}

The incidence of venous thromboembolism (VTE) is common, affecting approximately one person per 1,000 in the general population. ${ }^{1}$ Additionally, VTE is estimated to be the third most common cardiovascular disease after coronary heart disease and stroke, ${ }^{2}$ and VTE is often fatal. The prevention and treatment of VTE pose a major medical challenge. Antithrombotic substances have decreased the rates of venous and arterial thrombotic phenomena as well as their consequences. ${ }^{3,4}$ Examples of these substances include inhibitors of platelet aggregation and anticoagulant drugs. Orally active anticoagulants include vitamin $\mathrm{K}$ antagonists (VKAs) and non-vitamin $\mathrm{K}$ oral anticoagulants (NOACs) $)^{5-10}$ that do not oppose vitamin K. Parenteral anticoagulants include unfractionated heparin and low-molecular-weight heparins (LMWHs), ${ }^{11,12}$ 
which directly or indirectly exert their anticoagulant effects through one mechanism. Acetylsalicylic acid (aspirin) is an antiaggregant and anticoagulant via a number of mechanisms. ${ }^{13}$ The aim of this paper is to summarize new insights into the mechanisms of action of aspirin in the prevention of arterial and venous thrombosis. Arterial thrombosis can manifest as a heart attack or a stroke. Venous thrombosis can complicate orthopedic surgery or the course of malignant disease. In this manuscript, the role of aspirin in the prevention and treatment of primary and secondary VTE is reviewed.

\section{Aspirin}

Aspirin was discovered by Felix Hoffmann, a chemist in the pharmaceutical laboratory of the German manufacturer (Friedrich Bayer \& Co., Elberfeld, Germany). Hoffmann prepared the first pure sample of acetylsalicylic acid in August 1897, and it was marketed and registered under the trademark name aspirin in $1899 .{ }^{14}$ After oral administration, aspirin is rapidly absorbed from the stomach and upper small intestine, and the oral bioavailability of regular aspirin tablets is $40 \%-50 \%$ over a wide range of doses. The peak plasma level occurs 30-40 minutes after ingestion of ordinary aspirin tablets and 3-4 hours after ingestion of enteric-coated tablets. The inhibition of platelet function is dependent on the form of aspirin. ${ }^{15,16}$ Aspirin is widely used for the treatment of fever, migraines, and other conditions, including pain associated with inoperable cancer, rheumatoid arthritis, rheumatic fever, and acute tonsillitis. ${ }^{17}$

\section{Clinical indications of aspirin}

Currently, the clinical indications for the use of aspirin are as follows: primary prevention of cardiovascular events; prevention and treatment of primary and secondary stroke, as well as atrial fibrillation (AF) (to prevent stroke); treatment of acute ischemic stroke/transient ischemic attack (TIA); and prevention of secondary stroke/TIA ${ }^{18}$ However, according to Sato et al, a low dose of aspirin (150-200 mg per day) is not effective or safe in the prevention of ischemic stroke with AF. ${ }^{19}$ Other indications for the use of aspirin include acute coronary syndrome, peripheral artery disease, anterior myocardial infarction (MI) with left ventricular (LV) thrombus, anterior MI with high risk of LV thrombus, and mechanical heart valve. ${ }^{18}$ Aspirin is increasingly being applied to the prevention and treatment of thromboembolic phenomena, such as primary and secondary venous thrombosis, especially after major orthopedic surgery and other operations..$^{20}$

\section{Contraindications of aspirin}

The contraindications of aspirin are classified as absolute or relative. The absolute contraindications include active peptic ulcer, aspirin allergy, aspirin intolerance, hereditary bleeding disorders, thrombocytopenia, history of recent gastrointestinal bleeding, recent history of intracranial bleeding, renal impairment, and severe liver disease. The relative contraindications of aspirin include age younger than 21 years (increased risk of Reye syndrome), concurrent use of anticoagulation therapy, concurrent use of nonsteroidal anti-inflammatory drugs, and poorly controlled hypertension (risk of intracranial bleeding). ${ }^{21}$

\section{Mechanisms of action of aspirin}

Acetylsalicylic acid acts as an acetylating agent. Thus, aspirin irreversibly inactivates cyclooxygenase (COX)-1 and suppresses the generation of prostaglandin $\mathrm{H}_{2}$ (a precursor of thromboxane $\mathrm{A}_{2}$ ). Aspirin achieves this effect through its acetyl group, which becomes covalently attached to Ser529 of the active site of the COX-1 enzyme. ${ }^{22}$ Aspirin interacts with the amino acid Arg120 and consequently blocks the access of arachidonic acid to the hydrophobic channel to Tyr385 at the catalytic site. Thus, aspirin inhibits the generation of prostaglandin $\mathrm{H}_{2} \cdot{ }^{15}$ According to Undas et al, the antithrombotic effects of aspirin also involve the acetylation of other proteins of blood coagulation, including fibrinogen. Therefore, aspirin promotes fibrinolysis. ${ }^{13}$ Although aspirin can inhibit COX-2 by acetylating Ser516, this reaction is approximately 170 -fold slower than the reaction with COX-1. ${ }^{14}$ Lei et al reported the reaction with $\mathrm{COX}-2$ to be ten to 100 times slower than the reaction with COX-1. ${ }^{23}$ Aspirin produces an irreversible defect in thromboxane synthesis for the lifetime of affected platelets (8-10 days). ${ }^{24}$ The effect of aspirin on platelets is primarily related to downregulation of dense granule release. Alpha granule secretion is not impeded by COX-1 blockade in platelets that are stimulated by adenosine diphosphate (ADP) or thrombin. ${ }^{25}$ Only $10 \%$ of the platelet pool is replenished daily. Therefore, administration of aspirin in low doses can fully inhibit COX-1 (causing long lasting deffect), on repeat daily dosing, despite the fact that the half-life of aspirin is 15 to 20 minutes due to rapid presystemic hydrolysis that is catalyzed by esterase. ${ }^{15,26}$

Recent studies have explained the role and mechanisms of action of aspirin in the prevention of VTE. Aspirin-mediated prevention involves the inhibition of platelets. The binding of platelets and recruitment of neutrophils to the vascular endothelium is an early step in the development of deep vein thrombosis. ${ }^{27}$ Because the recruitment and rolling of 


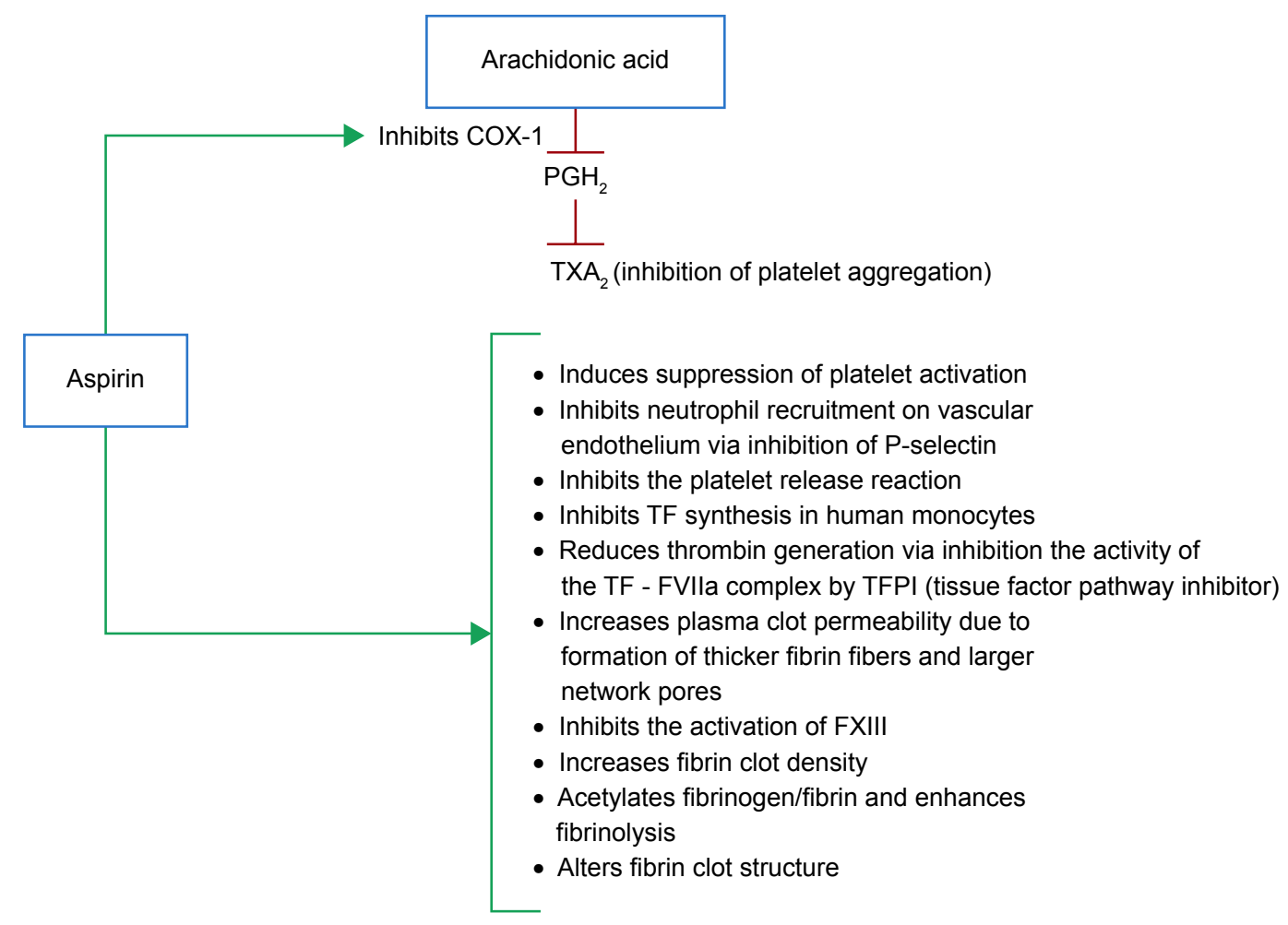

Figure I Mechanisms of antithrombotic effects of aspirin.

Abbreviations: $\mathrm{PGH}_{2}$, prostaglandin $\mathrm{H}_{2}$; TXA , thromboxane $\mathrm{A}_{2}$; COX-I, cyclooxygenase-I; TF, tissue factor; TFPI, tissue factor pathway inhibitor.

leukocytes, as well as their initial attachment to vascular endothelium, is dependent on a glycoprotein called P-selectin, the inhibition of P-selectin is associated with a reduced weight of mice subjected to thrombus induced by ligation of the inferior vena cava. ${ }^{28}$ Additionally, platelet inactivation by aspirin results in the inhibition of the release of the following platelet-associated substances into the venous circulation: platelet factors V and XIII, fibrinogen, platelet factors 3 and 4, thrombospondin, von Willebrand factor (vWF), calcium ions, serotonin, and other substances that favor the development of venous thrombosis. Enzymatic complexes (especially prothrombinase complex) form on the surfaces of activated platelets, and a large number of receptors are available for these complexes. ${ }^{13}$ Aspirin also prevents thrombin formation that is catalyzed by the calcium ion-dependent complex of tissue factor (TF) and activated factor VII (FVIIa). The inhibition of this complex by aspirin promotes the inhibition of factors IX and X. The formation of the prothrombinase complex and thrombin is subsequently inhibited. ${ }^{29}$ Thrombin is the serine protease that converts fibrinogen to fibrin, which polymerizes to form a thrombus. The inhibition of thrombin production by aspirin can be explained by two additional mechanisms, as follows: increased secretion of TF pathway inhibitor (TFPI) as well as the acetylation of prothrombin and several membrane components. ${ }^{30}$ Some authors have proposed that aspirin impacts the quality of fibrin within the thrombus. Properties of fibrin are dependent on the structural characteristics at the molecular level and at the level of individual fibers. The properties also depend on the arrangements of the three-dimensional networks. ${ }^{31}$ Acetylation of fibrinogen is an important mechanism of action of aspirin. Acetylation increases the porosity of the fibrin network and therefore increases the rate of fibrinolysis. ${ }^{32}$ The antithrombotic effect of high doses of aspirin potentially stems from reduced synthesis of coagulation factors in the liver, and this mechanism resembles those of VKAs. Furthermore, a reduction in thrombin levels reduces FXIII activation. ${ }^{33,34}$ The overall mechanisms of aspirin in the prevention and treatment of arterial and VTE are presented in Figure 1.

\section{The role of aspirin in the prevention of arterial thromboembolic events}

Until recently, aspirin has been considered to be a drug that prevents arterial thrombosis through COX-1 inhibition. ${ }^{35}$ One study has confirmed that aspirin therapy is suitable for the secondary prevention of cardiovascular events, ${ }^{36}$ but few clinical trials studying the efficacy of aspirin in the primary prevention of those events have been conducted. 
However, current guidelines define a role for aspirin in the primary prevention of cardiovascular events. ${ }^{37}$ The earliest events in thrombus formation are platelet adhesion followed by aggregation, platelet activation, and granule release. Except for platelet adhesion, all of these platelet functions are inhibited by aspirin. Thus, the drug reduces the risks of arterial thrombotic events. ${ }^{38}$ In a large number of atherosclerotic diseases (such as coronary, cerebrovascular, and peripheral arterial disease), aspirin and other antiplatelet drugs are the mainstays of treatment. ${ }^{39}$ According to six primary prevention trials performed by the Antithrombotic Trialists' (ATT) Collaboration, administration of aspirin leads to a $12 \%$ reduction in serious vascular events. ${ }^{40}$

Aspirin reduces nonfatal MIs by $20 \%$ but does not decrease ischemic strokes. ${ }^{40}$ In 16 secondary prevention trials, the same authors reported that aspirin therapy produces absolute reductions in vascular events, strokes, and coronary events, with percentages of $6.7 \%$ vs $8.2 \%$ per year $(P<0.0001), 2.08 \%$ vs $2.54 \%$ per year $(P=0.002)$, and $4.3 \%$ vs $5.3 \%$ per year $(P<0.0001)$, respectively. ${ }^{40}$ In their metaanalysis of nine trials involving 102,621 patients $(52,145$ in the aspirin group and 50,476 in the placebo/control group), Berger et al found that aspirin is associated with a reduction in major cardiovascular events with a risk ratio of $0.90(95 \%$ confidence interval $[\mathrm{CI}]$ : $0.85-0.96, P<0.001)$. However, these authors did not observe significant reductions of $\mathrm{MI}$, stroke, ischemic stroke, or all-cause mortality. ${ }^{41}$ Despite significant primary reductions in the rates of nonfatal MI (odds ratio [OR] 0.80; 95\% CI: 0.67-0.96), Seshasai et al found that aspirin prophylaxis does not reduce either cardiovascular death or cancer mortality in patients without prior cardiovascular disease. ${ }^{42}$

In general, aspirin should be administered once daily. The daily doses are based on international guidelines that depend on various clinical indications. According to the American College of Chest Physicians (ACCP), doses of aspirin in the range of 50-160 $\mathrm{mg}$ have value in the prevention and treatment of almost all cardiovascular diseases. In cases of mechanical heart valves, the recommended daily doses are $50-100 \mathrm{mg} .{ }^{43}$ For the primary prevention of cardiovascular events, anterior MI with LV thrombus, high risk of LV thrombus, acute coronary syndrome, and secondary stroke/TIA prevention, aspirin should be administered at daily doses of 75-100 mg. ${ }^{44}$ Higher doses of aspirin (75-325 mg) are needed to prevent stroke in AF and in peripheral artery disease. ${ }^{45,46}$ For the treatment of acute ischemic stroke/TIA, aspirin should be started at a daily dose of 160-325 mg within 48 hours. $^{47}$

\section{The role of aspirin in the prevention and treatment of venous thromboembolism}

Aspirin was initially appreciated in the prevention of arterial thrombosis. In 1977, aspirin (600 mg twice daily) was shown to reduce the risk of venous thrombosis in patients recovering from hip arthroplasty. ${ }^{48}$ Anderson et al examined the hip and knee registry for the period of 1996-2001, and they found that $4 \%-7 \%$ of patients received aspirin exclusively for thromboprophylaxis following primary total hip replacement, or total knee arthroplasty. ${ }^{49}$ Hovens et al summarized the evidence for the efficacy of aspirin in the prevention and treatment of VTE, and they concluded that further studies should examine the value of aspirin after a first unprovoked VTE. ${ }^{50}$ Two randomized controlled trials (the Warfarin and Aspirin [WARFASA] and the Aspirin to Prevent Recurrent Venous Thromboembolism [ASPIRE]) demonstrated that aspirin is suitable for long-term application to reduce the risk of recurrent VTE. The WARFASA trial is a multicenter, randomized, double-blinded study that included 403 patients previously treated with VKAs. Recurrent VTE occurred in 28 of the 205 patients treated with aspirin and in 43 of the 197 patients in the placebo group ( 2 weeks after withdrawal of VKAs), with percentages of $6.6 \%$ vs $11.2 \%$ per year, respectively (hazard ratio [HR] 0.58; 95\% CI: 0.36-0.93, $P=0.02) .{ }^{51}$ In the ASPIRE trial, 822 patients were treated with aspirin or placebo. As was the case in the WARFASA study, patients in the ASPIRE trial were previously treated with anticoagulants for 1.5-24 months due to spontaneous VTE or pulmonary embolism. The rate of recurrent VTE in patients treated with aspirin was $4.8 \%$ per year, and a rate of $6.5 \%$ per year occurred in the placebo group (HR 0.47; 95\% CI: 0.52-1.05). No significant difference in VTE incidence was noted between the aspirin and placebo groups $(P=0.09){ }^{52}$ Culić $^{53}$ and Paraskevas ${ }^{54}$ expressed concerns with regard to the impacts of sex and statins on the outcomes of the ASPIRE and WARFASA trials. The concerns are based on sex differences in platelet sensitivity to low doses of aspirin. ${ }^{55}$ Statins also influence the effect of aspirin on VTE. ${ }^{56}$ Simes et al reported that men have an increased risk of recurrent VTE compared with women. The risk also increases with advancing age. ${ }^{57}$ In the INSPIRE analysis, the same authors estimated the effect of aspirin treatment on VTE before and after adjustment of the baseline characteristics of the patients with similar HRs of 0.68 (95\% CI: $0.51-0.90, P=0.008)$ and 0.65 (95\% CI: $0.49-0.86, P=0.003$ ), respectively. These authors also analyzed the efficacy of aspirin in reducing 
Table I Recent studies on prevention of recurrent unprovoked VTE by aspirin

\begin{tabular}{|c|c|c|c|c|}
\hline Study & Type of trial & $\begin{array}{l}\text { Participants of the study and } \\
\text { their number }\end{array}$ & $\begin{array}{l}\text { Prior anticoagulant } \\
\text { treatment }\end{array}$ & VTE events \\
\hline WARFASA $^{50}$ & $\begin{array}{l}\text { Double-blinded } \\
\text { randomized } \\
\text { controlled trial }\end{array}$ & $\begin{array}{l}\text { Patients with previous } \\
\text { unprovoked VTE } \\
\text { Aspirin group }=205 \\
\text { Placebo group }=197\end{array}$ & At least 6 to 12 months & $\begin{array}{l}\text { VTE } \\
\text { Aspirin group }=28 \\
\text { Placebo group }=43 \\
(\mathrm{HR} 0.58,95 \% \mathrm{Cl}: 0.36-0.93, P=0.02)\end{array}$ \\
\hline ASPIRE $^{52}$ & $\begin{array}{l}\text { Double-blinded } \\
\text { randomized } \\
\text { controlled trial }\end{array}$ & $\begin{array}{l}\text { Patients with previous } \\
\text { unprovoked VTE } \\
\text { Aspirin group }=4 \mathrm{I} \mathrm{I} \\
\text { Placebo group }=4 \mathrm{I} \mathrm{I}\end{array}$ & $\begin{array}{l}\text { At least } 1.5 \text { to } 24 \\
\text { months }\end{array}$ & $\begin{array}{l}\text { VTE } \\
\text { Aspirin group }=28 \\
\text { Placebo group }=43 \\
(\mathrm{HR} 0.47,95 \% \mathrm{Cl}: 0.52-1.05, P=0.09)\end{array}$ \\
\hline INSPIRE ${ }^{56}$ & $\begin{array}{l}\text { A prospective } \\
\text { combined analysis } \\
\text { of the WARFASA } \\
\text { and ASPIRE trials }\end{array}$ & $\begin{array}{l}\text { Patients with previous } \\
\text { unprovoked VTE I,225 } \\
\text { randomized } \\
\text { Aspirin group }=616 \\
\text { Placebo group }=609\end{array}$ & $\begin{array}{l}\text { Patients were followed } \\
\text { up for at least } 2 \text { years } \\
\text { in the WARFASA trial } \\
\text { and up to } 4 \text { years in } \\
\text { ASPIRE }\end{array}$ & $\begin{array}{l}\text { VTE } \\
\text { Aspirin group }=8 \mathrm{I} \\
\text { Placebo group }=\mathrm{I} 12 \\
\text { BABC (HR } 0.68,95 \% \mathrm{Cl}: 0.5 \mathrm{I}-0.90, \\
P=0.008) \\
\text { AABC (HR } 0.65,95 \% \mathrm{Cl}: 0.49-0.86, \\
P=0.003)\end{array}$ \\
\hline $\begin{array}{l}\text { EINSTEIN CHOICE }{ }^{60} \\
\text { (Design of the } \\
\text { EINSTEIN CHOICE } \\
\text { study) }\end{array}$ & $\begin{array}{l}\text { Double-blinded } \\
\text { randomized } \\
\text { controlled trial }\end{array}$ & $\begin{array}{l}\text { Patients with previous } \\
\text { unprovoked VTE } 2,850 \text { patients } \\
\text { Rivaroxaban group }(10 \mathrm{mg})=950 \\
\text { Rivaroxaban group }(20 \mathrm{mg})=950 \\
\text { Aspirin group }(100 \mathrm{mg})=950\end{array}$ & At least 6 to 12 months & $\begin{array}{l}\text { This trial will be the first study to } \\
\text { compare the benefit-to-risk profile } \\
\text { of two doses ( } 10 \text { and } 20 \mathrm{mg} \text { ) of an } \\
\text { anticoagulant with that of aspirin for } \\
\text { extended VTE treatment }\end{array}$ \\
\hline
\end{tabular}

Abbreviations: $A A B C$, after adjustment of baseline characteristics; BABC, before adjustment of baseline characteristics; $\mathrm{Cl}$, confidence interval; HR, hazard ratio; VTE, venous thromboembolism.

the rate of recurrent DVT without symptomatic pulmonary embolism, and they found that aspirin decreases the rate of recurrent DVT by $34 \%$ without significantly increasing the risk of bleeding. ${ }^{57}$ Sobieraj et al performed a meta-analysis of ten trials $(n=11,079)$, and they found that various novel oral anticoagulants (NOACs) (apixaban at doses of 2.5 and $5 \mathrm{mg}$ as well as dabigatran and rivaroxaban) as well as idraparinux and VKAs each significantly reduced the risk of VTE recurrence with respect to placebo. All of the mentioned drugs, with the exception of idraparinux, more effectively prevented VTE than aspirin. However, the risk of bleeding was reduced in patients treated with aspirin. ${ }^{58}$ In a study on the extended (28-day regimen) use of aspirin prophylaxis to combat VTE after total hip arthroplasty, Anderson et al found that after administration of dalteparin prophylaxis for 10 days, aspirin treatment was not inferior $(P<0.001)$ or superior $(P=0.22)$ to continued dalteparin treatment for preventing VTE. ${ }^{59}$ According to Prandoni et al, low doses of aspirin offer a safe and cost-effective option for the long-term prevention of recurrent events in patients with unprovoked VTE, especially in patients without symptomatic atherosclerotic lesions.$^{60}$ Low-dose aspirin reduces the rates of recurrent VTE, but aspirin has not been previously compared with other anticoagulants. In the EINSTEIN CHOICE study, Weitz et al will compare rivaroxaban (10 and $20 \mathrm{mg}$ ) with aspirin (100 mg daily) for the prevention of symptomatic recurrent
VTE. The study will include 2,850 patients from 230 sites of 32 countries over a 27-month period. According to the EINSTEIN CHOICE Investigators, the trial will provide new insights into the optimal strategies for the extended treatment of VTE ${ }^{61}$ For the prevention of VTE and recurrent VTE as well as for prophylaxis against venous thromboembolic events after orthopedic surgery (long-term or extended VTE prophylaxis [VTEP]), aspirin is typically administered at the low, once-daily dose of $100 \mathrm{mg} .{ }^{51,52}$ The recent studies on prevention of recurrent unprovoked VTE by aspirin are presented in Table 1.

\section{The role of aspirin in the prevention of venous thromboembolism in orthopedic surgery}

VTE is an important and common complication after major orthopedic surgery. Bozic et al analyzed clinical data from 93,840 patients who underwent primary TKA during a 24-month period. Of those patients, 51,923 (55\%) received warfarin and 37,198 (40\%) were treated with injectable agents. However, only 4,719 (5\%) of these patients received aspirin. The patients who received aspirin for VTEP had lower risk for thromboembolism compared with patients administered warfarin, but the risk of VTE with aspirin as the preventive measure was similar to the risk when injectable VTEP was the measure. These results suggest that aspirin 
may be effective for VTEP for certain TKA patients when it is used in accordance with other clinical care protocols. ${ }^{62}$ Jiang et al compared the efficacies of aspirin (group A) and LMWHs followed by rivaroxaban (group B) in combination with mechanical postoperative measures in the prevention VTE after TKA, and they did not report any significant differences. In group A, ten of 60 patients (16.7\%) suffered a DVT (95\% CI: 7.3-26.1), and in group B (LMWHs/ rivaroxaban), eleven of 60 patients $(8.3 \%)$ suffered a DVT (95\% CI: 8.5-27.8) $(P=0.500) .{ }^{63}$ The American Academy of Orthopaedic Surgeons (AAOS) and the ACCP offer guidelines for the use of aspirin for the prophylaxis of VTE events in patients recovering from orthopedic surgery. Consistent with the guidelines, many surgeons select aspirin for VTEP, especially in patients undergoing TKA. ${ }^{64}$ According to Knesek et al, the most recent AAOS and ACCP guidelines allow considerable autonomy in the choice of prophylactic agents (VKAs, NOACS, and LMWHs) for thromboembolic prophylaxis following total joint arthroplasty. ${ }^{65}$ In view of independent observational studies that identified minimal difference between LMWHs and aspirin, the National Institute for Health and Clinical Excellence (NICE) guidelines may be overly reliant on assumptions and may warrant revision. ${ }^{66}$

\section{Adverse effects of aspirin}

Increased bleeding is the most frequent and important side effect of aspirin. Gastrointestinal bleeding is reported in approximately $3 \%$ of elderly patients treated with aspirin. ${ }^{67}$ To reduce the incidence of this adverse effect of aspirin, it is reasonable to prescribe low doses of enteric-coated aspirin. The risk of major gastrointestinal events is increased by $30 \%$, to $70 \%$ over the overall baseline risk of 0.7 per 1,000 per year that is observed with low- or standard-dose aspirin was compared with enteric-coated aspirin (to prevent gastrointestinal bleeding). ${ }^{67}$ Although hemorrhagic strokes are rare, they are the most serious side effect and are potentially fatal. It is estimated that hemorrhagic strokes occur at a rate of $0.03 \%$ per year in aspirin users. ${ }^{40}$ Additionally, hematologic side effects, such as hypoprothrombinemia, ${ }^{68}$ thrombocytopenia, ${ }^{69}$ and pancytopenia, have been rarely reported. ${ }^{70}$ Other side effects of aspirin include renal, dermatologic, hepatic, oncologic, musculoskeletal, cardiovascular, and respiratory problems. Hypersensitivity to aspirin can also occur.

\section{Conclusion}

Many recent randomized controlled trials have indicated that aspirin achieves its antithrombotic effects through more mechanisms than previously realized. Aspirin is a promising drug for the prevention of recurrent unprovoked VTE, and its long-term use does not carry a great risk of major bleeding. Other advantages of aspirin include its low cost, once-daily application, and lack of need for dose monitoring.

\section{Disclosure}

The authors report no conflicts of interest in this work.

\section{References}

1. Silverstein MD, Heit JA, Mohr DN, Petterson TM, O'Fallon WM, Melton LJ 3rd. Trends in the incidence of deep vein thrombosis and pulmonary embolism: a 25-year population-based study. Arch Intern Med. 1998;158(6):585-593.

2. Goldhaber SZ. Pulmonary embolism thrombolysis: a clarion call for international collaboration. J Am Coll Cardiol. 1992;19(2): 246-247.

3. Patrono C, Rocca B. Aspirin, 110 years later. J Thromb Haemost. 2009; 7 Suppl 1:258-261.

4. Gómez-Outes A, Suárez-Gea ML, Calvo-Rojas G, et al. Discovery of anticoagulant drugs: a historical perspective. Curr Drug Discov Technol. 2012;9(2):83-104.

5. Ferlund P, Stenflo J, Roepstorff P, Thomsen J. Vitamin K and the biosynthesis of prothrombin. V. Gamma-carboxyglutamic acids, the vitamin Kdependent structures in prothrombin. $J$ Biol Chem. 1975;250(15): 6125-6133.

6. Hirsh J, Dalen JE, Anderson DR, et al. Oral anticoagulants: mechanism of action, clinical effectiveness, and optimal therapeutic range. Chest. 1998; 114:445S-469S.

7. Klauser W, Dütsch M. Practical management of new oral anticoagulants after total hip or total knee arthroplasty. Musculoskelet Surg. 2013;97(3):189-197.

8. Connolly SJ, Ezekowitz MD, Yusuf S, et al; RE-LY Steering Committee and Investigators. Dabigatran versus warfarin in patients with atrial fibrillation. $N$ Engl J Med. 2009;361(12):1139-1151.

9. da Silva RM. Novel oral anticoagulants in non-valvular atrial fibrillation. Cardiovasc Hematol Agents Med Chem. 2014;12(1): 3-8.

10. Mekaj YH, Mekaj AY, Duci SB, Miftari EI. New oral anticoagulants: their advantages and disadvantages compared with vitamin $\mathrm{K}$ antagonists in the prevention and treatment of patients with thromboembolic events. Ther Clin Risk Manag. 2015;11:967-977.

11. Hirsh J, Anand SS, Halperin JL, Fuster V. Mechanism of action and pharmacology of unfractionated heparin. Arterioscler Thromb Vasc Biol. 2001;21(7):1094-1096.

12. Weitz JI. Low-molecular-weight heparins. NEngl J Med. 1997;337(10): 668-698.

13. Undas A, Brummel-Ziedins K, Mann KG. Why does aspirin decrease the risk of venous thromboembolism? On old and novel antithrombotic effects of acetyl salicylic acid. J Thromb Haemost. 2014; 12(11):1176-1187.

14. Sneader W. The discovery of aspirin: a reappraisal. BMJ. 2000; 321(7276):1591-1594.

15. Patrono C, Coller B, FitzGerald FA, Hirsh J, Roth G. Platelet-active drugs: the relationship among dose, effectiveness, and side effects: the Seventh ACCP Conference on Antithrombotic and Thrombolytic Therapy. Chest. 2004;126(3 Suppl):234S-264S.

16. Pedersen AK, FitzGerald GA. Dose-related kinetics of aspirin. Presystemic acetylation of platelet cyclooxygenase. $N$ Engl J Med. 1984;311(19):1206-1211.

17. Wilthauer J, Wohlgemut J. Uber aspirine (acetylsalicylic acid). Ther Mh (Halbmh). 1899;13:276. German. 
18. Eikelboom JW, Hirsh J, Spencer FA, Baglin TP, Weitz JI. Antiplatelet drugs: Antithrombotic Therapy and Prevention of Thrombosis, 9th ed: American College of Chest Physicians Evidence-Based Clinical Practice Guidelines. Chest. 2012;141(2 Suppl):e89S-e119S.

19. Sato H, Ishikawa K, Kitabatake A, et al; Japan Atrial Fibrillation Stroke Trial Group. Low-dose aspirin for prevention of stroke in low-risk patients with atrial fibrillation: Japan Atrial Fibrillation Stroke Trial. Stroke. 2006;37:447-451.

20. [No authors listed]. Prevention of pulmonary embolism and deep vein thrombosis with low dose aspirin: Pulmonary Embolism Prevention (PEP) trial. Lancet. 2000;355(9212):1295-1302.

21. Miser WF. Appropriate aspirin use for primary prevention of cardiovascular disease. Am Fam Physician. 2011;83(12):1380-1386.

22. Tóth L, Muszbek L, Komáromi I. Mechanism of the irreversible inhibition of human cyclooxygenase-1 by aspirin as predicted by QM/MM calculations. J Mol Graph Model. 2013;40:99-109.

23. Lei J, Zhou Y, Xie D, Zhang Y. Mechanistic insights into a classic wonder drug - aspirin. J Am Chem Soc. 2015;137(1):70-73.

24. Maree AO, Fitzgerald DJ. Variable platelet response to aspirin and clopidogrel in atherothrombotic disease. Circulation. 2007;115(16): 2196-2207.

25. Rinder CS, Student LA, Bonan JL, Rinder HM, Smith BR. Aspirin does not inhibit adenosine diphosphate-induced platelet alpha-granule release. Blood. 1993;82(2):505-512.

26. Patrignani P, Filabozzi P, Patrono C. Selective cumulative inhibition of platelet thromboxane production by low-dose aspirin in healthy subjects. J Clin Invest. 1982;69(6):1366-1372.

27. Fuchs TA, Brill A, Wagner DD. Neutrophil extracellular trap (NET) impact on deep vein thrombosis. Arterioscler Thromb Vasc Biol. 2012 32(8):1777-1783.

28. Meier TR, Myers DD Jr, Wrobleski SK, et al. Prophylactic P-selectin inhibition with PSI-421 promotes resolution of venous thrombosis without anticoagulation. Thromb Haemost. 2008;99(2):343-351.

29. Butenas S, Orfeo T, Mann KG. Tissue factor in coagulation: Which? Where? When? Arterioscler Thromb Vasc Biol. 2009;29(12): 1989-1996.

30. Szczeklik A, Krzanowski M, Góra P, Radwan J. Antiplatelet drugs and generation of thrombin in clotting blood. Blood. 1992;80(8): 2006-2011.

31. Brown AE, Litvinov RI, Discher DE, Purohit PK, Weisel JW. Multiscale mechanics of fibrin polymer: gel stretching with protein unfolding and loss of water. Science. 2009;325(5941):741-744.

32. Lord ST. Molecular mechanisms affecting fibrin structure and stability. Arterioscler Thomb Vasc Biol. 2011;31(3):494-499.

33. Loew D, Vinazzer H. Dose-dependent influence of acetylsalicylic acid on platelet functions and plasmatic coagulation factors. Haemostasis. 1976;5(4):239-249.

34. Undas A, Sydor WJ, Brummel K, Musial J, Mann KG, Szczeklik A. Aspirin alters the cardioprotective effects of the factor XIII Val34Leu polymorphism. Circulation. 2003;107(1):17-20.

35. Warkentin TE. Aspirin for dual prevention of venous and arterial thrombosis. N Engl J Med. 2012;367(21):2039-2041.

36. Yasue H, Ogawa H, Tanaka H, et al. Effects of aspirin and trapidil on cardiovascular events after acute myocardial infarction. Japanese Antiplatelets Myocardial Infarction Study (JAMIS) Investigators. Am J Cardiol. 1999;83(9):1308-1313.

37. Ittaman SV, VanWormer JJ, Rezkalla SH. The role of aspirin in the prevention of cardiovascular disease. Clin Med Res. 2014;12(3-4):147-154.

38. Ho LL, Brighton T. Warfarin, antiplatelet drugs and their interactions. Aust Prescr. 2002;25:81-85.

39. Morimoto T, Nakayama M, Saito Y, Ogawa H. Aspirin for primary prevention of atherosclerotic disease in Japan. J Atheroscler Thromb. 2007;14(4):159-166.

40. Antithrombotic Trialists' (ATT) Collaboration, Baigent C, Blackwell L, et al. Aspirin in the primary and secondary prevention of vascular disease: collaborative meta-analysis of individual participant data from randomised trials. Lancet. 2009;373(9678):1849-1860.
41. Berger JS, Lala A, Krantz MJ, Baker GS, Hiatt WR. Aspirin for the prevention of cardiovascular events in patients without clinical cardiovascular disease: a meta-analysis of randomized trials. Am Heart J. 2011;162(1):115-124.e2.

42. Seshasai SR, Wijesuriya S, Sivakumaran R, et al. Effect of aspirin on vascular and nonvascular outcomes: meta-analysis of randomized controlled trials. Arch Intern Med. 2012;172(3):209-216.

43. Whitlock RP, Sun JC, Fremes SE, Rubens FD, Teoh KH; American College of Chest Physicians. Antithrombotic and thrombolytic therapy for valvular disease: Antithrombotic Therapy and Prevention of Thrombosis, 9th ed: American College of Chest Physicians Evidence-Based Clinical Practice Guidelines. Chest. 2012;141(2 Suppl): e576S-e600S.

44. Vandvik PO, Lincoff AM, Gore JM, et al; American College of Chest Physicians. Primary and secondary prevention of cardiovascular disease: Antithrombotic Therapy and Prevention of Thrombosis, 9th ed: American College of Chest Physicians Evidence-Based Clinical Practice Guidelines. Chest. 2012;141(2 Suppl):e637S-e668S.

45. You JJ, Singer DE, Howard PA, et al; American College of Chest Physicians. Antithrombotic therapy for atrial fibrillation: Antithrombotic Therapy and Prevention of Thrombosis, 9th ed: American College of Chest Physicians Evidence-Based Clinical Practice Guidelines. Chest. 2012;141(2 Suppl):e531S-e575S.

46. Smith SC Jr, Benjamin EJ, Bonow RO, et al; World Heart Federation and the Preventive Cardiovascular Nurses Association. AHA/ACCF Secondary Prevention and Risk Reduction Therapy for patients with Coronary and other Atherosclerotic Vascular Disease: 2011 update: a guideline from the American Heart Association and American College of Cardiology Foundation. Circulation. 2011;124(22):2458-2473.

47. Lansberg MG, O’Donnell MJ, Khatri P, et al; American College of Chest Physicians. Antithrombotic and thrombolytic therapy for ischemic stroke: Antithrombotic Therapy And Prevention Of Thrombosis, 9th ed: American College of Chest Physicians EvidenceBased Clinical Practice Guidelines. Chest. 2012;141(2 Suppl): e601S-e636S.

48. Harris WH, Salzman EW, Athanasoulis CA, Waltman AC, DeSanctis RW. Aspirin prophylaxis of venous thromboembolism after total hip replacement. $N$ Engl J Med. 1977;297(23):1246-1249.

49. Anderson FA Jr, Hirsh J, White K, Fitzgerald RH Jr; Hip and Knee Registry Investigators. Temporal trends in prevention of venous thromboembolism following primary total hip or knee arthroplasty 1996-2001: findings from the Hip and Knee Registry. Chest. 2003;124(6 Suppl): 349S-356S.

50. Hovens MM, Snoep JD, Tamsma JT, Huisman MW. Aspirin in the prevention and treatment of venous thromboembolism. J Thromb Haemost. 2006;4(7):1470-1475.

51. Becattini C, Agnelli G, Schenone A, et al; WARFASA Investigators. Aspirin for preventing the recurrence of venous thromboembolism. N Eng J Med. 2012;366(21):1959-1967.

52. Brighton TA, Eikelboom JW, Mann K, et al; ASPIRE Investigators. Low-dose aspirin for preventing recurrent venous thromboembolism. N Engl J Med. 2012;367(21):1979-1987.

53. Culić V. Aspirin for preventing venous thromboembolism. $N$ Engl J Med. 2013;368(8):772.

54. Paraskevas KI. Aspirin for preventing venous thromboembolism. N Engl J Med. 2013;368(8):772-773.

55. Becker DM, Segal J, Vaidya D, et al. Sex differences in platelet reactivity and response to low-dose aspirin therapy. JAMA. 2006;295(12): 1420-1427.

56. Khemasuwan D, Chae YK, Gupta S, et al. Dose-related effect of statins in venous thrombosis risk reduction. Am J Med. 2011;124(9): $852-859$.

57. Simes J, Becattini C, Agnelli G, et al; INSPIRE Study Investigators (International Collaboration of Aspirin Trials for Recurrent Venous Thromboembolism). Aspirin for the prevention of recurrent venous thromboembolism: the INSPIRE collaboration. Circulation. 2014;130(13): 1062-1071. 
58. Sobieraj DM, Coleman CI, Pasupuleti V, Deshpande A, Kaw R, Hernandez AV. Comparative efficacy and safety of anticoagulants and aspirin for extended treatment of venous thromboembolism: a network meta-analysis. Thromb Res. 2015;135(5):888-896.

59. Anderson DR, Dunbar MJ, Bohm ER, et al. Aspirin versus low-molecularweight heparin for extended venous thromboembolism prophylaxis after total hip arthroplasty: a randomized trial. Ann Intern Med. 2013; 158(11):800-806.

60. Prandoni P, Noventa F, Milan M. Aspirin and recurrent venous thromboembolism. Phlebology. 2013;28 Suppl 1:99-104.

61. Weitz JI, Bauersachs R, Beyer-Westendorf J, et al; EINSTEIN CHOICE Investigators. Two doses of rivaroxaban versus aspirin for the prevention of recurrent venous thromboembolisms. Rationale for and design of the EINSTEIN CHOICE study. Thromb Haemost. 2015;114(3): $645-650$.

62. Bozic KJ, Vail TP, Pekow PS, Maselli JH, Lindenauer PK, Auerbach AD. Does aspirin have a role in venous thromboembolism prophylaxis in total knee arthroplasty patients? J Arthroplasty. 2010;25(7): 1053-1060.

63. Jiang Y, Du H, Liu J, Zhou Y. Aspirin combined with mechanical measures to prevent venous thromboembolism after total knee arthroplasty: a randomized controlled trial. Chin Med J (Engl). 2014;127(12): 2201-2205.
64. Stewart DW, Freshour JE. Aspirin for the prophylaxis of venous thromboembolic events in orthopedic surgery patients: a comparison of the AAOS and ACCP guidelines with review of the evidence. Ann Pharmacother. 2013;47(1):63-74.

65. Knesek D, Peterson T, Markel DC. Thromboembolic prophylaxis in total joint arthroplasty. Thrombosis. 2012;2012:837-896.

66. Jameson SS, Baker PN, Deehan DJ, Port A, Reed MR. Evidence-base for aspirin as venous thromboembolic prophylaxis following joint replacement. Bone Joint Res. 2014;3(5):146-149.

67. Thorat MA, Cuzick J. Prophylactic use of aspirin: systematic review of harms and approaches to mitigation in the general population. Eur J Epidemiol. 2015;30(1):5-18.

68. Fausa O. Salicylate-induced hypoprothrombinemia. A report of four cases. Acta Med Scand. 1970;188(5):403-408.

69. Garg SK, Sarker CR. Aspirin-induced thrombocytopenia on an immune basis. Am J Med Sci. 1974;267(2):129-132.

70. Wijnja L, Snijder JA, Nieweg HO. Acetylsalicylic acid as a cause of pancytopenia from bone-marrow damage. Lancet. 1996;2(7467): $768-770$.
Therapeutics and Clinical Risk Management

\section{Publish your work in this journal}

Therapeutics and Clinical Risk Management is an international, peerreviewed journal of clinical therapeutics and risk management, focusing on concise rapid reporting of clinical studies in all therapeutic areas outcomes, safety, and programs for the effective, safe, and sustained use of medicines. This journal is indexed on PubMed Central, CAS,

\section{Dovepress}

EMBase, Scopus and the Elsevier Bibliographic databases. The manuscript management system is completely online and includes a very quick and fair peer-review system, which is all easy to use. Visit http://www.dovepress.com/testimonials.php to read real quotes from published authors. 